\title{
Mother-to-Child Transmission of HIV and Its Predictors Among HIV-Exposed Infants at an Outpatient Clinic for HIV/AIDS in Vietnam
}

This article was published in the following Dove Press journal: HIVIAIDS - Research and Palliative Care

\author{
Rang Ngoc Nguyen (D) ${ }^{1,2}$ \\ Quang Chanh Ton ${ }^{2}$ \\ Quang Hien Tran $\mathbb{1}^{2}$ \\ Thi Kieu Linh Nguyen ${ }^{2}$ \\ 'Department of Pediatrics, Can Tho \\ University of Medicine and Pharmacy, \\ Can Tho, Vietnam; ${ }^{2}$ Women and \\ Children Hospital of an Giang, An Giang, \\ Vietnam
}

Background: Mother-to-child transmission (MTCT) of human immunodeficiency virus (HIV) is decreasing worldwide; however, achieving the MTCT elimination target of $2 \%$ by 2020 and $0 \%$ by 2030 is challenging in resource-limited countries. The purpose of this study is to determine the evolution of the HIV transmission rate in infants from 2007 to 2018 and to identify the risk factors of HIV transmission among HIV-exposed infants in Vietnam.

Patients and Methods: A prospective cohort study of 608 HIV-exposed infants was conducted at the Pediatric Outpatient Clinic (pOPC) of the Women and Children Hospital of An Giang, Vietnam between September 2007 and December 2019. A follow-up registration book was used to collect data, which were entered into Microsoft Excel and analyzed by SPSS version 22.0. Both bivariate and multivariate analyses were carried out to identify associations.

Results: A total of 608 HIV-exposed infant were enrolled in the study, of which 472 were included in the final analysis. The median age of infants at enrollment to follow-up was 6.3 weeks (interquartile range $[\mathrm{IQR}]=6.0-6.9$ weeks). A total of 42 infants out of 472 were infected with HIV, giving an overall MTCT rate of $8.9 \%(95 \%$ confidence interval $(\mathrm{CI})=6.4-12.0)$. The transmission rate decreased from $27.9 \%$ in 2007 to $0 \%$ in 2018. Absence of maternal ARV (antiretrovirals) intervention before or during pregnancy $(\mathrm{AOR}=40.6,95 \% \mathrm{CI}=5.5-308)$ and absence of $\mathrm{ARV}$ prophylaxis for HIV-exposed infants $(\mathrm{AOR}=3.4,95 \% \mathrm{CI}=1.1-10.3)$ were significantly and independently associated with MTCT of HIV in this study.

Conclusion: There is a significant progress on the reduction of MTCT rate in An Giang, Vietnam. Absence of ART interventions for mothers and infants are significant factors associated with HIV transmission. Providing free ARV and increasing the coverage of ARV intervention for pregnant women are keys for reducing the MTCT rate in the future.

Keywords: HIV-exposed infants, antiretrovirals, MTCT of HIV, Vietnam

\section{Introduction}

The transmission of humnan immunodeficiency virus (HIV) from a HIV-positive mother to her child during pregnancy, labor, delivery, or breastfeeding is called mother-to-child transmission (MTCT). In the absence of any intervention, transmission rates range from $15-45 \% .{ }^{1}$ Globally, this accounts for $90 \%$ of HIV infections in children under the age of 15 years. $^{2}$ In Vietnam, by 2007 more than 220,000 persons were estimated to have been HIV infected, including 3750 children infected perinatally. ${ }^{3}$

With a campaign to reduce the rate of children infected with HIV, the Vietnam Ministry of Health has promoted a program on prevention of mother-to-child
Correspondence: Rang Ngoc Nguyen Tel +84913106404

Email nguyenngocrang@gmail.com 
transmission (PMTCT) of HIV integrated into the existing maternal and child health service to help reduce MTCT of HIV and to decrease both maternal and child mortality since 2002. ${ }^{4,5}$ In addition, a nationwide scale-up of a free antiretroviral therapy (ART) program began in 2005 through a network of HIV outpatient clinics (OPCs).

An Giang province, which is located in the Mekong Delta region of Vietnam, and which shares an international border with Cambodia, is the province with the fifth highest HIV prevalence rate in Vietnam. ${ }^{6}$ The Pediatric Outpatient Clinic (pOPC) of the Women and Children Hospital of An Giang has started both treatment for HIVinfected children and prevention for exposed-HIV infants since 2006, This service has been funded by Leadership and Investment in Fighting an Epidemic-Global AIDS Program (LIFE-GAP), the US President's Emergency Plan for AIDS Relief (PEPFAR), and the National Target Program for HIV/AIDS Prevention and Control. ${ }^{7}$

Protocols for prevention of MTCT were based on National Guidelines for Diagnosis and Treatment of HIV/ AIDS of the Vietnam Ministry of Health and WHO Guidelines. $^{8,10}$

For maternal ARV intervention, Option A was adopted in Vietnam in 2005. In this regimen, zidovudine (AZT) treatment started at the 14th week of gestation, a single dose of nevirapine (sdNVP) was provided during labor and daily doses of AZT were given for 7 days postpartum. By 2011, Option B was adopted, which consisted of a combination of triple ARV (cARV) provided to the mother from the 14th week of gestation to delivery, and a sdNVP was provided during labor, and daily doses of AZT were given for 4-6 weeks postpartum. By the end of 2015, Vietnam adopted Option B+, which provides lifelong cARV to all HIV-infected pregnant and breastfeeding women, irrespective of CD4 count or clinical WHO stage. $^{8,9}$

Although there are several reports on the effectiveness and outcomes of PMTCT from many countries, there are still limited studies conducted in Vietnam to assess the rate of MTCT of HIV and its predictors among HIV-exposed infants. In one study conducted in Thai Nguyen, Vietnam, the authors reported that the rate of transmission decreased from $27.3 \%$ in 2008 to $6.7 \%$ in $2012 .^{11}$

The purpose of this study is to determine the evolution of the HIV transmission rate in infants from 2007 to 2018 and to identify risk factors of HIV transmission among HIV-exposed infants at one pOPC in An Giang province, Vietnam.

\section{Patients and Methods}

\section{Study Design and Setting}

A prospective cohort study was conducted between August 2007 and May 2019, at the pOPC of the Women and Children Hospital of An Giang, located in the Mekong Delta, Vietnam. This pOPC was established in 2006 and it has both treated HIV-infected children and prevented HIV MTCT.

\section{Study Population and Samples}

All 608 HIV-exposed infants, paired with their 603 HIVinfected mothers (5 pairs of twins), were enrolled in the study. These infants were either born at the Obstetrics Ward of the Women and Children Hospital of An Giang or transferred from other healthcare facilities in the province for suspicion of contracting HIV. Samples comprised of 472 infants who had a final confirmed HIV test at 18 months of age. There were 136 infants excluded from the study because of missing data or who were lost to followup (LTFU).

\section{Data Collection}

Data were collected using a structured data collection format. The independent variables were age of enrollment, gender (male or female), type of delivery (cesarean or vaginal), area of residence (rural, urban), maternal ARV prior to pregnancy (no, yes), maternal ART (monotherapy AZT or cARV) intervention during pregnancy (no, yes), ART received at delivery (no, yes), and ART prophylaxis (nevirapine or zidovudine) for newborns. The dependent variable was the HIV status (positive, negative) of the HIV-exposed infant at the age of 18 months.

Data were double-checked by a second reviewer for quality and accuracy. Twins of mother were counted twice.

\section{Follow-Up}

According to the guidelines, the follow-up schedule of infants born to HIV-positive mothers is at 6 hours, 24 hours after birth, and the 7th day of life at postnatal MTCT clinic. HIV-exposed infants were placed on ARV prophylaxis immediately after birth. The protocols for ARV prophylaxis during the study period are presented in Table 1.

HIV testing of HIV-exposed infants was done at 6 weeks of age, or earlier for those who lived far away from the clinic. A dried blood spot sampling from infants was collected and sent to Pasteur Institute, Ho Chi Minh City for qualitative analysis of HIV DNA by polymerase chain reaction (PCR) assays. The infant was declared 
Table I Protocols for Prevention of MTCT from 2007 to 2018 at pOPC of the Women and Children Hospital of An Giang

\begin{tabular}{|l|l|l|}
\hline Before 2010 & From 2010 to 2015 & After 2015 \\
\hline Mother: & Mother: & Mother: \\
Antepartum AZT from I4 weeks onward + sdNVP during labor + & Antepartum cARV combination from & $\begin{array}{l}\text { Antepartum cARV (from Ist HIV } \\
\text { + test) for life }\end{array}$ \\
$\begin{array}{l}\text { InfT for 7 days postpartum } \\
\text { sdNVP and AZT for I weeks }\end{array}$ & 14 weeks onward & Infant: \\
Infant: & sdNVP + AZT for 4 weeks & NVP for 6 weeks \\
\hline
\end{tabular}

Abbreviations: AZT, zidovudine; sdNVP, single dose of nevirapine; cARV, combination of triple antiretrovirals.

positive for HIV if the PCR testing was positive. All first positive results were confirmed by a second PCR test.

Thereafter, the follow-up was on a monthly basis until the age of 18 months for asymptomatic infants (negative PCR test at 6 weeks of age). Cotrimoxazole prophylaxis was usually started when the infant was 4-6 weeks old. Infant formulas were provided free of charge for up to 18 months of age. No laboratory tests were performed at each visit unless infants were ill. After 18 months of follow-up, rapid tests for detecting antibodies (using Determine HIV-1/2 or SD Bioline test kits) were performed to confirm the HIV status (positive, negative). All positive results with an antibody test were confirmed by a HIV PCR test.

\section{Operational Definition}

-HIV-Exposed Infants (HEIs): Infants born to HIVpositive mothers.

-HIV-Infected Infants: Infant born to HIV-positive mothers and having two positive PCR tests or having a positive antibody test at or after 18 months of age.

-Lost to follow-up (LTFU): Infants with missing data, transfer to another OPC, death (negative HIV test) and no HIV antibody test at 18 months of age.

\section{Ethical Issue}

Parents and caregivers signed informed consent forms on first attending the pOPC. This study was approved by the Science and Technology Board of the Women and Children Hospital of An Giang (reference No: 31a-QĐBVSN). The ethical issues of the study were revised every 5 years. The study was conducted in accordance with the Declaration of Helsinki. Patient confidentiality was assured.

\section{Statistical Analysis}

The data were entered into a Microsoft Excel database and analyzed using SPSS version 22.0. Categorical variables were expressed as numbers and percentages, continuous variables were expressed as median and interquartile range. MTCT rate was estimated in proportion with $95 \%$ confidence intervals (CI). Chi-square tests were used to compare the two proportions and the rank-based nonparametric Kendall's taub test was used to detect statistically significant trends in the proportion of MTCT over time.

Bivariate and multivariate logistic regression were performed to determine associations between independent variables and dependents variable (HIV status of exposed infants) were performed. Odds ratio (OR) with a 95\% CI was used to measure the degree of association with infant HIV positivity. $P$-values less than 0.05 were considered statistically significant.

\section{Results}

A total of 608 infants from 603 mothers (5 twins) were enrolled at pOPC during the study period. PCR tests were done by the age of 6 weeks for 608 infants, of which 40 infected-HIV infants received cARV treatment and 568 uninfected-HIV infants were followed up at the pOPC. At the end of the 18-month follow-up, 136 infants were lost to follow-up (two of them had a positive PCR test at the age of 6 weeks): 12 were transferred to other OPCs, two died with negative PCR tests, 116 were not present to pOPC at 18 months of age, and six missed clinical records. In addition, at the end of the 18 month followup, two infants of the remaining 472 were positive with an HIV antibody test (confirmed by PCR test), raising the total of HIV-infected infants to 42.

\section{Socio-Demographic Characteristics of HEls and Their Mothers}

Among 608 infants at enrolment, the median age to HIVexposed infant was 6.3 weeks ( $\mathrm{IQR}=6.0-6.9$ weeks). $47.7 \%$ of them were males and $70.2 \%$ of them were from rural areas. Vaginal delivery accounted for $66.6 \%$. 
Table 2 Socio-Demographic and Characteristics of Exposed-HIV Infants and Their Mothers

\begin{tabular}{|l|l|l|l|}
\hline Variables & Categories & Frequency & Percentage \\
\hline $\begin{array}{l}\text { Age at enrollment } \\
(\mathrm{n}=608)\end{array}$ & $\begin{array}{l}\leq 6 \text { weeks } \\
>6 \text { weeks }\end{array}$ & 167 & 27.5 \\
\hline $\begin{array}{l}\text { Gender } \\
(\mathrm{n}=608)\end{array}$ & Male & 441 & 72.5 \\
\hline $\begin{array}{l}\text { Residence } \\
(\mathrm{n}=608)\end{array}$ & Female & 290 & 47.7 \\
\hline $\begin{array}{l}\text { Type of delivery (n=592) } \\
\end{array}$ & Urban & 318 & 52.3 \\
\hline $\begin{array}{l}\text { Maternal ARV intervention } \\
(\mathrm{n}=603)\end{array}$ & Cesarean & 427 & 70.2 \\
& Vaginal & 181 & 29.8 \\
\hline $\begin{array}{l}\text { None } \\
\text { sdNVP at delivery } \\
(n=608)\end{array}$ & sdNVP+AZT for 7 days & 198 & 33.4 \\
& Already on ART & 394 & 66.6 \\
\hline & None & 137 & 22.7 \\
\hline & $\begin{array}{l}\text { sdNVP+ AZT for 7 days } \\
\text { sdNVP+AZT for 4 weeks } \\
\text { NVP for 6 weeks }\end{array}$ & 29 & 4.8 \\
\hline
\end{tabular}

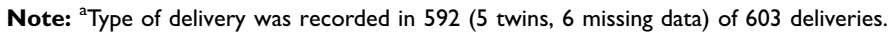

Abbreviations: sdNVP, single dose nevirapine; AZT, zidovudine; ART, Aantiretroviral therapy.

There were $279(46.3 \%)$ of 603 mothers receiving ARV, of which 157 (26.0\%) were receiving ARV prior to pregnancy, and $122(20.3 \%)$ were receiving ARV during pregnancy. There were $29(4.8 \%)$ mothers receiving sdNVP at delivery and $158(26.2 \%)$ mothers receiving sdNVP+AZT for 7 days after delivery. The remaining $137(22.7 \%)$ mothers did not receive any ARV intervention.

The majority $(87.7 \%)$ of HIV-exposed infants received sdNVP and AZT for 7 days or 4 weeks or NVP for 6 weeks after birth. The remaining $12.3 \%$ of exposed infants did not receive any ARV prophylaxis (Table 2).

\section{Coverage of ART Intervention for Women and ARV Prophylaxis for Infants}

After excluding LTFU infants, the remaining 472 children were included in the final analysis. The number of women receiving ART, the number of infants receiving ARV prophylaxis, the proportion of women on ART, the proportion of infant ARV prophylaxis, the number of HIV-infected infants, and the MTCT rate each year from 2007 to 2018 are presented in Table 3.

The proportion of ART coverage for pregnant women gradually increased from $11.1 \%(2 / 18)$ in 2007 to $81.0 \%$
$(17 / 21)$ in 2018 (Kendall's tau-b=0.406, $P=0.000)$ and the proportion of ARV prophylaxis for infants varied from $62.5 \%(20 / 32)$ to $100 \%(21 / 21)$ during the study period (Kendall's tau- $\mathrm{b}=0.160, P=0.000$ ).

\section{Mother to Child Transmission Rate}

Of the 472 HIV-exposed infants, 42 were infected with HIV, giving an transmission rate of $8.9 \%$ (confidence interval: $95 \% \mathrm{CI}=6.4-12.0)$. The transmission rate decreased from $27.9 \%(5 / 18)$ in 2007 to $0 \%(0 / 21)$ in 2018. There were statistically significant trends in decrease of MTCT rate over time (Kendall's tau- $b=-0.105$, $P=0.004$ ) (Figure 1).

Of 229 women who were on ART before delivery, 157 $(56.3 \%)$ received ART prior to pregnancy and $122(43.7 \%)$ received ART during pregnancy; the median time to start ARV was 22 weeks of gestational age $(\mathrm{IQR}=16-28$ weeks). Only one infant whose mother received monotherapy AZT intervention at 15 weeks of gestational age had HIV-positive status after 18-month follow-up. The MTCT rate in women who were on ART before delivery was $0.43 \%(1 / 229)$.

After intervention (increased HIV testing for pregnant women since 2014 and introduction of Option B+ since 2015), the MTCT rate of HIV dropped dramatically from $11.4 \%(33 / 289)$ to $4.9 \%(9 / 183)\left(X^{2}=5.84, P=0.016\right)$. 
Table 3 Percentage of Women on ART, Percentage of Infant ARV Prophylaxis, and MTCT Rate from 2007 to 2018 at pOPC, An Giang, Vietnam

\begin{tabular}{|l|l|l|l|l|l|l|l|l|l|l|l|l|l|}
\hline Years & $\mathbf{2 0 0 7}$ & $\mathbf{2 0 0 8}$ & $\mathbf{2 0 0 9}$ & $\mathbf{2 0 1 0}$ & $\mathbf{2 0 I I}$ & $\mathbf{2 0 1 2}$ & $\mathbf{2 0 1 3}$ & $\mathbf{2 0 1 4}$ & $\mathbf{2 0 1 5}$ & $\mathbf{2 0 1 6}$ & $\mathbf{2 0 1 7}$ & $\mathbf{2 0 1 8}$ & Total \\
\hline $\mathrm{N}_{\mathrm{w} 1}$ & 2 & 3 & $\mathrm{I}$ & 8 & 26 & 30 & 23 & 38 & 39 & 20 & 22 & 17 & 229 \\
\hline $\mathrm{N}_{\mathrm{w} 2}$ & 18 & 32 & 34 & 34 & 64 & $5 \mathrm{I}$ & 56 & 52 & 50 & 27 & 30 & 21 & 469 \\
\hline $\mathrm{P}_{\mathrm{w}}$ & $\mathrm{II} .1$ & 9.4 & 2.9 & 23.5 & 40.6 & 58.8 & 41.1 & 73.1 & 78.0 & 74.1 & 73.3 & 81.0 & 48.8 \\
\hline $\mathrm{N}_{\mathrm{cl}}$ & 17 & 20 & 28 & 31 & 55 & 42 & 44 & 49 & 49 & 28 & 29 & 21 & 413 \\
\hline $\mathrm{N}_{\mathrm{c} 2}$ & 18 & 32 & 34 & 34 & 64 & 51 & 56 & 52 & 52 & 28 & 30 & 21 & 472 \\
\hline $\mathrm{Pc}$ & 94.4 & 62.5 & 82.4 & 91.2 & 85.9 & 82.4 & 78.6 & 94.2 & 94.2 & 100 & 96.7 & 100 & 87.5 \\
\hline $\mathrm{Ni}$ & 5 & 1 & 2 & 6 & 8 & 6 & 5 & 5 & 3 & 0 & 1 & 0 & 42 \\
\hline $\mathrm{MTCTR}$ & 27.9 & 3.1 & 5.9 & 17.6 & 12.5 & 11.8 & 8.9 & 9.6 & 5.8 & 0.0 & 3.3 & 0.0 & 8.9 \\
\hline
\end{tabular}

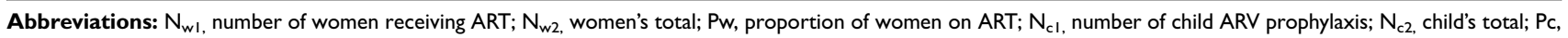
proportion of child ARV prophylaxis; Ni, number of HIV-infected children; MTCTR, mother-to-child transmission rate.

\section{Factors Associated with MTCT of HIV}

The bivariate analysis showed that mothers without ARV intervention or infants without receiving NVP/AZT prophylaxis after birth were associated with increased MTCT rate. Other variables (age at enrolment, gender, place of birth, and type of delivery) were not associated with HIV positive outcome of infants (Table 4).

Multivariate logistic regression analysis revealed that the odds of HIV transmission to the infants were 40.6-times higher in mothers without ARV intervention compared to mothers with ARV intervention prior to

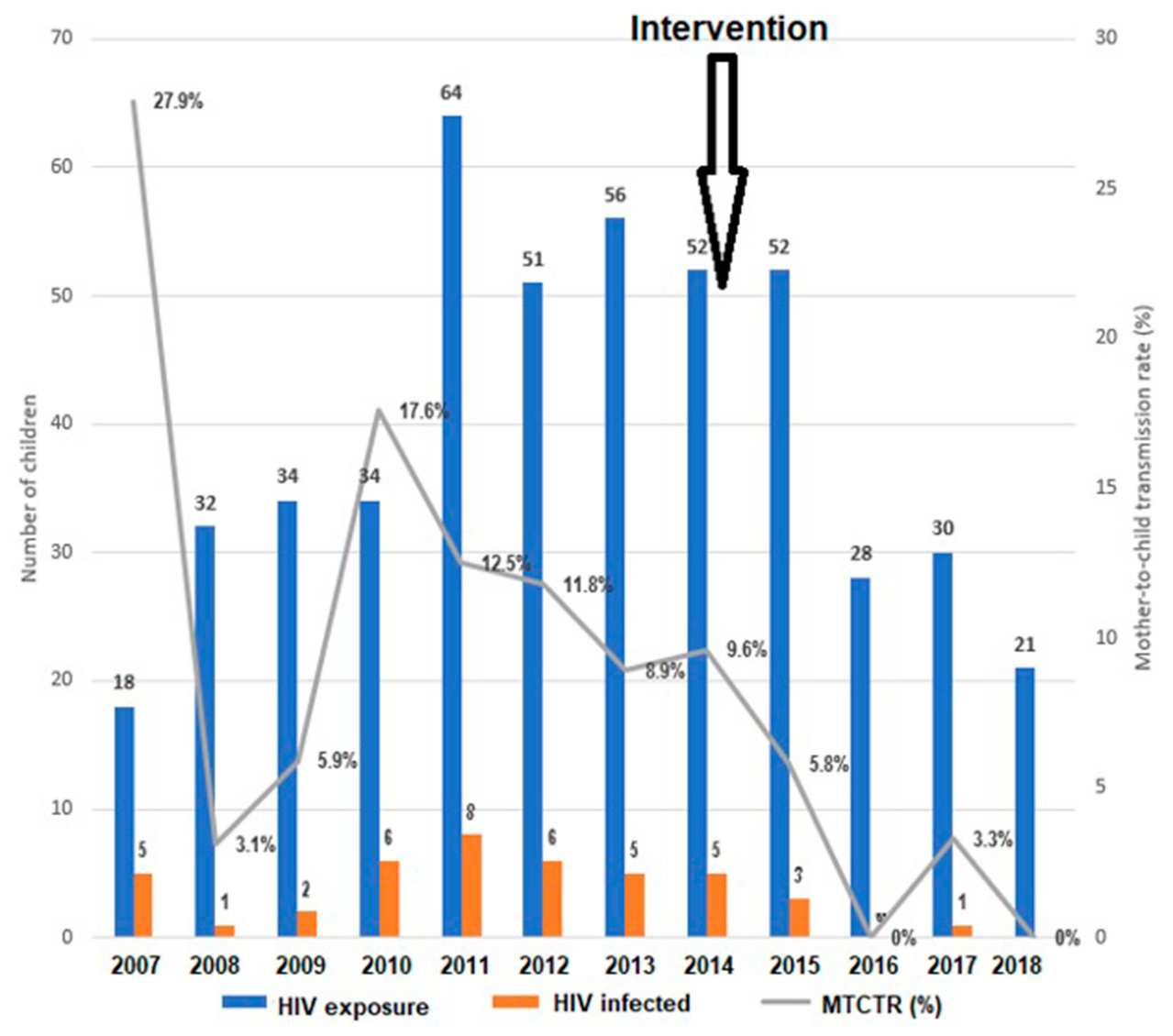

Figure I Mother-to-child transmission (MTCT) rates of HIV in An Giang, Vietnam from 2007 to 2018. 
Table 4 Bivariate and Multivariate Analysis of Factors Associated with MTCT of HIV on 473 HEls at the Women and Children Hospital of An Giang, Vietnam

\begin{tabular}{|c|c|c|c|c|}
\hline \multirow[t]{2}{*}{ Variables } & \multicolumn{2}{|l|}{ HIV Status } & \multirow[t]{2}{*}{ Crude OR $(95 \% \mathrm{Cl})$} & \multirow[t]{2}{*}{ Adjusted OR (95\% Cl) } \\
\hline & Positive n (\%) & Negative $\mathbf{n}(\%)$ & & \\
\hline \multicolumn{5}{|l|}{ Age at enrollment $(n=472)$} \\
\hline$\leq 6$ weeks & $7(5.0)$ & $132(95,0)$ & 1.0 & 1.0 \\
\hline$>6$ weeks & $35(10.5)$ & $298(89.5)$ & $2.21(0.95-5.11)$ & $1.27(0.51-3.18)$ \\
\hline \multicolumn{5}{|l|}{ Gender $(n=472)$} \\
\hline Male & $16(7.5)$ & $198(92.5)$ & 1.0 & 1.0 \\
\hline Female & $26(10.1)$ & $232(89.9)$ & $1.38(0.72-2.65)$ & $1.64(0.79-3.40)$ \\
\hline \multicolumn{5}{|l|}{ Residence $(n=472)$} \\
\hline Rural & $29(8.8)$ & $300(91.2)$ & 1.0 & 1.0 \\
\hline Urban & $13(9.1)$ & $130(90.9)$ & $1.03(0.52-2.05)$ & $1.08(0.50-2.30$ \\
\hline \multicolumn{5}{|l|}{ Type of delivery $(n=46 \mathrm{I})^{\mathrm{a}}$} \\
\hline Cesarean & $12(7.2)$ & $154(92.8)$ & 1.0 & 1.0 \\
\hline Vaginal & $28(9.4)$ & $270(90.6)$ & $1.33(0.65-2.69)$ & $0.96(0.44-2.08)$ \\
\hline \multicolumn{5}{|l|}{ Maternal ARV intervention } \\
\hline Yes $^{\mathrm{b}}$ & $41(17.1)$ & $199(82.9)$ & $46.5(6.4-344)$ & $40.6(5.5-308)$ \\
\hline \multicolumn{5}{|l|}{ No } \\
\hline \multicolumn{5}{|l|}{ Infant ARV intervention $(n=472)$} \\
\hline NVP 6 weeks & $6(3.8)$ & I5I (96.2) & 1.0 & 1.0 \\
\hline sdNVP+AZT 4 weeks & $12(7.5)$ & $148(92.5)$ & $2.2(0.7-6.7)$ & I. I.I(0.3-3.3) \\
\hline sdNVP+AZT I week & $8(8.2)$ & $89(91.8)$ & $2.0(0.7-5.5)$ & I. $0.6(0.2-1.9) 3.4(1.1-10.3)$ \\
\hline No & $16(27.6)$ & $42(72.4)$ & $9.5(3.5-26.0)$ & \\
\hline
\end{tabular}

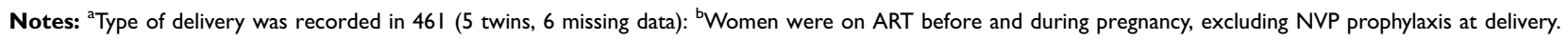
Abbreviations: ARV, antiretrovirals; OR, odds ratio.

delivery $(\mathrm{AOR}=40.6,95 \% \mathrm{CI}=5.5-308)$. Likewise, the odds of being HIV positive were 3.4-times higher among infants not receiving ARV than the infants who received NVP prophylaxis for 6 weeks after birth $(\mathrm{AOR}=3.4,95 \%$ $\mathrm{CI}=1.1-10.3$ ). Infants receiving sdNVP and AZT (1 or 4 weeks) did not decrease the odds of being HIV positive as compared to infants without ARV prevention (Table 4).

\section{Discussion}

This study shows the overall rate of MTCT of HIV was $8.9 \%$ in our setting from 2007 to 2018 . This rate is higher than that of many recent studies done across the world; ${ }^{12-17}$ however, the rate of MTCT, which was reduced from $27.9 \%$ in 2007 to $0 \%$ in 2018, achieved the MTCT elimination target of $2 \%$ by 2020 as recommended by $\mathrm{WHO}$ and by the Vietnam National Strategy on HIV/AIDS Prevention and Control. ${ }^{18}$

In our study, the rate of MTCT has been decreasing through time in parallel with the increased coverage of
ART intervention for women during pregnancy. Similar results were observed in Thai Nguyen, Vietnam ${ }^{11}$ and in other Asian countries. In a prospective study during 2004-2011 in eight counties in China, Wang et al ${ }^{19}$ reported that vertical transmission of HIV declined from 11.2 to $1.2 \%$, corresponding to an increase in ART coverage for pregnant women from $61 \%$ to $96 \%$. Thailand became the first country in Asia to validate the elimination of MTCT by meeting WHO targets; the MTCT rate decreased from $>20 \%$ to $1.9 \%$, while the HIV-positive pregnant women receiving ART for prevention of MTCT increased from $71.4 \%$ in 2001 to $95.6 \%$ in $2015 .^{20}$ In Africa, during the analysis of 32 countries with generalized HIV epidemics, Hill et $\mathrm{al}^{21}$ noticed that an average $10 \%$ increase in PMTCT coverage was related to a $3-3.5 \%$ reduction in $\mathrm{MTCT}$ rate.

The successful implementation of the PMTCT program in our setting is due to good communication among pOPC, antenatal care clinic, delivery wards, and postnatal facilities. In addition, the supply of ARV drugs and infant formulas free 
of charge has contributed to the favorable outcome. Moreover, the adoption of Option $\mathrm{B}+$ since 2015 has resulted in an increase in ARV coverage for pregnant women. This figure is consistent with other studies in African countries. ${ }^{12,22}$

Nevertheless, the coverage of ART (81\%) intervention for pregnant women in our setting has not yet met the target of $>90 \%$ using ARV, which was lower than the number in many countries in Africa ${ }^{12,14,16}$ and in Asia, ${ }^{19,20}$ where the coverage of ART intervention for pregnant women ranged from 91$96 \%$. Maintenance and a gradual increase in maternal ARV coverage to attain the elimination target of zero transmission of HIV from mother to child by 2030 are challenging. Equipment of PCR assays at local institutions, free of charge provision of ARV drugs through healthcare insurance, and decentralisation of ART services in our province may be the solution of the PMTCT program in the future. ${ }^{12,23,24}$

The shift of the PMTCT from option A to option B+ improved the MTCT rate in our setting. In a cohort study in Ukraine, Bailey et $\mathrm{al}^{13}$ found that $\mathrm{CARV}$ was associated with a $70 \%$ greater reduction in the risk of MTCT. Many studies worldwide showed that the adoption of Option B+ had contributed to a decrease in the rate of MTCT of HIV. ${ }^{16,25-29}$

During the 12-year follow-up of this cohort, of 229 women who were on ART before or during pregnancy, only one child $(0.43 \%)$ whose mother received AZT monotherapy (Option A) had HIV-positive at the age of 18 months. This finding is consistent with the study of Kesho Bora Group; they found that the mothers who received AZT monotherapy were less effective in PMTCT than those receiving triple ARV. ${ }^{30}$

In multivariable logistic regression analysis, two independent factors associated with MTCT rate of HIV in the present study were absence of maternal ARV intervention and absence of ARV prophylaxis for HIV-exposed infants after birth. HIVpositive mothers who were on ART were 40.5-times less likely to transmit HIV than those who were not on ART. This finding is similar to studies conducted in different corners of the world which confirm that maternal ART intervention is the determinant factor for reducing MTCT rate. ${ }^{17,19,27,29,31-35}$

By the same token, HIV-exposed infants with ARV prophylaxis after birth were 3.4-times less likely to be HIV-infected at the age of 18 months. This finding was in line with previous studies in Africa. ${ }^{17,27,34}$ Even on women without receiving ARV during pregnancy, earlier studies reported that infant ARV prophylaxis also decreased HIV transmission rates. ${ }^{36-38}$

The strength of the current study is that it is a prospective cohort study, with all mothers and infants visiting pOPC every month for check-up, and getting ARV drugs and infant formulas, so that the recall bias was avoided. Nevertheless, this study has certain limitations. First, our cohort study was followed up over a long period of time, resulting in many lost-tofollow-up cases which can affect the internal validity of the MTCT rate estimation. Second, all potential factors were not included and assessed, the fact of which may affect the generalization of predictors in this study. Third, the lack of data on measurement of ART adherence may affect on estimation of MTCT rate. Finally, free formula supplies were stopped for the last 3 years of this cohort study even though infants were encouraged to avoid breastfeeding until 18 months of age.

\section{Conclusions}

There has been significant progress on the reduction of the rate of HIV transmission from mother to child in An Giang, Vietnam. ART interventions for mothers and infants are significant factors associated with HIV transmission reduction. Providing free ARV and increasing the coverage of ART intervention for pregnant women are keys for reducing the MTCT rate in the future.

\section{Abbreviations}

ART, Antiretroviral Therapy; ARV, Antiretrovirals; AZT, zidovudine; cARV, combination of triple antiretrovirals; NVP, nevirapine; pOPC, Pediatric Outpatient Clinic; MTCT, Mother-to-child transmission of HIV; PMTCT, Prevention of mother-to-child transmission; sdNVP, single dose of nevirapine; WHO, World Heath Organization.

\section{Acknowledgments}

We thank Tai Huynh, MD, MMM for English editing, and Nguyen Thi Hoang for collecting the data.

\section{Author Contributions}

All authors made substantial contributions to the conception and design, acquisition of data, or analysis and interpretation of data; took part in drafting the article or revising it critically for important intellectual content; agreed to submit to the current journal; gave final approval of the version to be published; and agree to be accountable for all aspects of the work.

\section{Funding}

This research did not receive any specific grant from funding agencies in the public, commercial, or not-forprofit sectors. 


\section{Disclosure}

The authors report no conflicts of interest in this work.

\section{References}

1. World Health Organization. Available from: https://www.who.int/hiv/ topics/mtct/en/. Accessed February 2, 2020.

2. De Cock KM, et al. Prevention of mother-to-child HIV transmission in resource-poor countries: translating research into policy and practice. JAMA, 2000. 283(9):1175-1182. doi:10.1001/ jama.283.9.1175

3. Vietnam Ministry of Health. Viet nam HIV/AIDS estimates and Projections; 2007-2012. Available from: https://www.ilo.org/ wcmsp5/groups/public/_ed_protect/—protrav/_ilo_aids/docu ments/legaldocument/wcms_174609.pdf. Accessed January 8, 2020.

4. Vietnam Ministry of Health, AIDS Division. Sentinel Surveillance Data, 1994-2002. Hanoi; 2002.

5. Vietnam Ministry of Health, Health Statistics \& Informatics Division. Health Statistics Year Book 2001. Hanoi; 2002.

6. Thuy TT, Shah NS, Anh MH, et al. HIV-associated TB in An Giang Province, Vietnam, 20012004: epidemiology and TB treatment outcomes. PLoS One. 2007; 2(6):e507. doi:10.1371/journal.pone.0000507

7. Ministry of Health. National Strategy on HIV/AIDS Prevention and Control in Vietnam Till 2010 with a Vision to 2020. Hanoi: Medical Publishers; 2004.

8. Ministry of Health. National guidelines for diagnosis and treatment of HIV/AIDS. Ministry of health; 2009. Available from: http://www. bvtwqn.vn/Portals/0/Images/Documents/2014/KhoaYHN\%C4\%90/ HIV.AIDS-BYT.2009.pdf. Accessed January 8, 2020.

9. Vietnam Ministry of Health. National Guidelines for HIV/AIDS Managment, Diagnosis and Treatment. Hanoi: Viet Nam Ministry of Health; 2015.

10. World Health Organization. Prevention of mother-to-child transmission, briefing note; [Updated October 1st,2007]. Available from: https://www.who.int/hiv/pub/toolkits/PMTCT\%20HIV\%20Dept\% 20brief\%200ct\%2007.pdf. Accessed on February 2, 2020.

11. Nguyen TTV, Sabin K, Ho TQT, Le AKA, Hayashi C, Kato M Monitoring prevention impact of mother-to-child transmission of HIV in concentrated epidemics with program and survey data. JMIR Public Health Surveill. 2017;;3(4):e76. doi:10.2196/ publichealth. 7701

12. Tippett Barr BA, van Lettow M, van Oosterhout JJ, et al. National estimates and risk factors associated with early mother-to-child transmission of HIV after implementation of option B+: a cross-sectional analysis. Lancet HIV. 2018; 5(12):e688-e695. doi:10.1016/S23523018(18)30316-3

13. Bailey H, Townsend CL, Semenenko I, et al. Impact of expanded access to combination antiretroviral therapy in pregnancy: results from a cohort study in Ukraine. Bull World Health Organ. 2013; 91 (7):491-500. doi:10.2471/BLT.12.114405

14. Goga AE, Dinh T, Jackson D, et al. First population-level effectiveness evaluation of a national programme to prevent HIV transmission from mother to child, South Africa. J Epidemiol Community Health. 2015;69:240-248. doi:10.1136/jech-2014-204535

15. Muyunda B, Musonda P, Mee P, Todd J, Michelo C Effectiveness of lifelong ART (Option B+) in the prevention of mother-to-child transmission of HIV programme in Zambia: observations based on routinely collected health data. Front Public Health. 2020; 17;7:401. doi:10.3389/fpubh.2019.00401

16. Pellowski J, Wedderburn C, Stadler JAM, et al. Implementation of prevention of mother-to-child transmission (PMTCT) in South Africa: outcomes from a population-based birth cohort study in Paarl, Western Cape. BMJ Open. 2019;;9(12):e033259. doi:10.1136/ bmjopen-2019-033259
17. Yitayew YA, Bekele DM, Demissie BW, Menji ZA Mother to child transmission of HIV and associated factors among HIV exposed infants at public health facilities, Dessie Town, Ethiopia. HIV AIDS. $2019 ; 12 ; 11: 343-350$.

18. Vietnam Government. The Government of Vietnam. Approving the National Strategy on HIV/AIDS prevention and control in Viet Nam till 2010 with a vision to 2020. Hanoi; 2012 [Updated September 26, 2017]. Available from: http://vaac.gov.vn/Cms_Data/Contents/VaacEn/Media/Documents/nationalstrategy.pdf. Accessed February 3, 2020.

19. Wang Q, Wang L, Fang L, et al. Timely antiretroviral prophylaxis during pregnancy effectively reduces HIV mother-to-child transmission in eight counties in China: a prospective study during 20042011. Sci Rep. 2016; 10;6:34526. doi:10.1038/srep34526

20. Lolekha R, Boonsuk S, Plipat T, et al. Elimination of mother-to-child transmission of HIV -Thailand. MMWR Morb Mortal Wkly Rep. 2016;;65(22):562-566. doi:10.15585/mmwr.mm6522a2

21. Hill A, Dauncey T, Levi J, Heath K, Pérez Casas C Higher risks of mother-to-child HIV transmission in countries with lower HIV prevalence: UNAIDS 2013 results for 32 countries with generalised epidemics. J Virus Erad. 2015; 1;1(4):257-263. doi:10.1016/00062944(75)90147-7

22. Kieffer MP, Mattingly M, Giphart A, et al. Lessons learned from early implementation of option B+: the Elizabeth Glaser Pediatric AIDS Foundation experience in 11 African countries. $J$ Acquir Immune Defic Syndr. 2014; 1;67 Suppl 4:S188-94. doi:10.1097/ QAI.0000000000000372

23. Sherman GG, Cooper PA, Coovadia AH, et al. Polymerase chain reaction for diagnosis of human immunodeficiency virus infection in infancy in low resource settings. Pediatr Infect Dis J. 2005; 24 (11):993-997. doi:10.1097/01.inf.0000187036.73539.8d

24. Pachanee CA, Wibulpolprasert S Incoherent policies on universal coverage of health insurance and promotion of international trade in health services in Thailand. Health Policy Plan. 2006;21(4):310-318. doi:10.1093/heapol/czl017

25. Abimpaye M, Kirk CM, Iyer HS, et al. The impact of "Option B" on HIV transmission from mother to child in Rwanda: an interrupted time series analysis. PLoS One. 2018;;13(2):e0192910. doi:10.1371/ journal.pone. 0192910

26. Gong T, Wang H, He X, Liu J, Wu Q, Wang J Investigation of prevention of mother to child HIV transmission program from 2011 to 2017 in Suzhou, China. Sci Rep. 2018;;8(1):18071. doi:10.1038/ s41598-018-36623-6

27. Gueye SB, Diop-Ndiaye H, Diouf O, et al. Effectiveness of the prevention of HIV mother -to-child transmission (PMTCT) program via early infant diagnosis (EID) data in Senegal. PLoS One. 2019;;14 (5):e0215941. doi:10.1371/journal.pone.0215941

28. Ghoma Linguissi LS, Sagna T, Soubeiga ST, et al. Prevention of mother-to-child transmission (PMTCT) of HIV: a review of the achievements and challenges in Burkina-Faso. HIV AIDS. 2019; 24;11:165-177.

29. Moges NA, Kassa GM, Boneya DJ Rate of HIV transmission and associated factors among HIV-exposed infants in selected health facilities of East and West Gojjam Zones, Northwest Ethiopia; retrospective cohort study. BMC Infect Dis. 2017;;17(1):475. doi:10.1186/ s12879-017-2578-3

30. de Vincenzi I. Kesho Bora Study Group. Triple antiretroviral compared with zidovudine and single-dose nevirapine prophylaxis during pregnancy and breastfeeding for prevention of mother-to-child transmission of HIV-1 (Kesho Bora study): a randomised controlled trial. Lancet Infect Dis. 2011;11(3):171-180.

31. Do Prado TN, Brickley DB, Hills NK, Zandonade E, Moreira-Silva SF, Miranda AE. Factors associated with maternal-child transmission of HIV-1 in Southeastern Brazil: a retrospective study. AIDS Behav. 2018; 22(Suppl 1):92-98. doi:10.1007/s10461-018-2172-8 
32. Dinh TH, Mushavi A, Shiraishi RW, et al. Impact of timing of antiretroviral treatment and birth weight on mother-to-child human immunodeficiency virus transmission: findings from an 18-month prospective cohort of a nationally representative sample of mother-infant pairs during the transition from option A to Option B+ in Zimbabwe. Clin Infect Dis. 2018;;66(4):576-585. doi:10.1093/cid/cix820

33. Fondoh VN, Mom NA Mother-to-child transmission of HIV and its predictors among HIV-exposed infants at Bamenda Regional Hospital, Cameroon. Afr J Lab Med. 2017;;6(1):589. doi:10.4102/ ajlm.v6i1.589

34. Kassa GM Mother-to-child transmission of HIV infection and its associated factors in Ethiopia: a systematic review and meta-analysis. BMC Infect Dis. 2018;18(1):216. doi:10.1186/ s12879-018-3126-5

35. Koye DN, Zeleke BM Mother-to-child transmission of HIV and its predictors among HIV-exposed infants at a PMTCT clinic in northwest Ethiopia. BMC Public Health. 2013; 27;13:398. doi:10.1186/ 1471-2458-13-398
36. Connor EM, Sperling RS, Gelber R, et al. Reduction of maternal-infant transmission of human immunodeficiency virus type 1 with zidovudine treatment. Pediatric AIDS clinical trials group protocol 076 Study Group. $N$ Engl J Med. 1994; 331 (18):1173-1180. doi:10.1056/NEJM199411033311801

37. Petra Study Team. Efficacy of three short-course regimens of zidovudine and lamivudine in preventing early and late transmission of HIV-1 from mother to child in Tanzania, South Africa, and Uganda (Petra study): a randomised, double-blind, placebo-controlled trial. Lancet. 2002; 359(9313):1178-1186 doi:10.1016/S0140-6736(02) 08214-4

38. Shaffer N, Chuachoowong R, Mock PA, et al. Short-course zidovudine for perinatal HIV-1 transmission in Bangkok, Thailand: a randomised controlled trial. Bangkok collaborative perinatal HIV transmission study group. Lancet. 1999; 353(9155):773-780 doi:10.1016/S0140-6736(98)10411-7

HIV/AIDS - Research and Palliative Care

\section{Publish your work in this journal}

HIV/AIDS - Research and Palliative Care is an international, peerreviewed open-access journal focusing on advances in research in HIV, its clinical progression and management options including antiviral treatment, palliative care and public healthcare policies to control viral spread. The manuscript management system is completely online and includes a very quick and fair peer-review system, which is all easy to use. Visit http://www.dovepress.com/testimonials.php to read real quotes from published authors. 